\title{
Effects of microzooplankton growth and trophic interactions on herbivory in coastal and offshore environments
}

\author{
Matthew R. First ${ }^{1,4, *}$, Harlan L. Miller III ${ }^{1}$, Peter J. Lavrentyev ${ }^{2}$, \\ James L. Pinckney ${ }^{3}$, Adrian B. Burd ${ }^{1}$ \\ ${ }^{1}$ Department of Marine Sciences, The University of Georgia, Marine Science Building, Athens, Georgia 30602, USA \\ ${ }^{2}$ Department of Biology, The University of Akron, Akron, Ohio 44325, USA \\ ${ }^{3}$ Marine Science Program and Department of Biological Sciences, University of South Carolina, Columbia, \\ South Carolina 29208, USA
}

${ }^{4}$ Present address: Department of Geology and Geophysics, Woods Hole Oceanographic Institute, Woods Hole, Massachusetts 02543, USA

\begin{abstract}
We performed serial dilution experiments to estimate rates of gross phytoplankton growth $(\mu)$ and grazing mortality $(m)$ in both eutrophic (Corpus Christi Bay, Texas, USA) and oligotrophic (offshore Gulf of Mexico) waters. Two parallel experiments were performed in both environments, with seawater pre-screened through 153 or $25 \mu \mathrm{m}$ mesh to observe the responses of microzooplankton (MZP) to dilution treatments. MZP biomass changed over the duration of the experimental incubations; in several treatments, MZP net growth rates were $>1 \mathrm{~d}^{-1}$. Patterns of growth varied between dilutions and initial screening size. In the eutrophic system, the ratio of phytoplankton grazing mortality rate to gross phytoplankton growth rate $(\mathrm{m} / \mu)$ was $1.10 \pm 0.54$ (mean $\pm \mathrm{SD}$ ) versus $0.41 \pm$ 0.65 when screened through 153 and $25 \mu \mathrm{m}$ mesh, respectively. This difference was attributed to cascading trophic interactions among MZP size groups leading to suppression of the primary herbivores in the $25 \mu \mathrm{m}$ fraction and, in turn, a lower value of $\mathrm{m}$. A food web model consisting of multiple trophic levels was constructed to examine the role of MZP growth and trophic interactions on measurements of $\mu$ and $\mathrm{m}$. The model, using 3 interacting groups of MZP, was able to reproduce experimental results. Model simulations demonstrated that MZP growth during incubation leads to an overestimation of $m$. Non-linearity in the phytoplankton growth response curves was due to MZP growth and trophic interactions in these model simulations, as variable feeding responses were not incorporated into the models. Trophic interactions among MZP can provide context to measurements of $\mu$ and $m$ and insight into microbial food web efficiency.
\end{abstract}

KEY WORDS: Serial dilution experiments · Microbial food web · Microplankton · Food web model · Ciliates $\cdot$ Dinoflagellates $\cdot$ Trophic cascades $\cdot$ Zooplankton

\section{INTRODUCTION}

The majority of oceanic primary production is carried out by microalgae that are effectively too small or dispersed to directly support microinvertebrates (Stoecker \& Capuzzo 1990, Sherr \& Sherr 2002). A large portion of this oceanic primary production is consumed by microzooplankton (MZP), a collection of phagotrophic protists and microinvertebrates $<200 \mu \mathrm{m}$ in size (Calbet \& Landry 2004). MZP are critically important in channeling marine primary production to the metazoan food web. Consequently, estimating the grazing impact of MZP on phytoplankton is central to understanding carbon flow and the fate of primary production in marine systems.

The overall impact of MZP is often determined by serial dilution experiments. In this method, the predator-prey encounter rate is progressively decreased by 
diluting the microbial community with particle-free water (Landry \& Hassett 1982). Phytoplankton growth is assumed to be controlled only by grazers, so that the lower encounter rates in diluted samples result in higher phytoplankton net growth. Further assuming that the population of grazers remains constant during each incubation allows for the MZP-specific grazing rate $(m)$ and gross phytoplankton growth rate $(\mu)$ to be estimated from a linear regression of dilution level and net phytoplankton growth rate.

A central feature of serial dilution experiments is the inclusion of the entire MZP community. This yields a composite effect of the natural assemblage of herbivores that is likely more reflective of in situ dynamics than herbivory rates determined from controlled experiments using a reduced number of taxa. However, the results of serial dilution experiments do not reflect all potential trophic interactions among MZP. For example, many large ciliates and dinoflagellates selectively consume heterotrophic nanoflagellates (Premke \& Arndt 2000, Christoffersen \& Gonzalez 2003), and cascading trophic interactions have been observed among organisms in the pico- to microplanktonic size range, indicating the presence of multiple trophic levels among MZP (Reckermann \& Veldhuis 1997, Calbet et al. 2001).

MZP include organisms with high growth rates (Banse 1982). Growth rates of herbivorous MZP can approach and surpass those of phototrophic protists in temperate waters (Rose \& Caron 2007). Therefore, MZP communities potentially respond rapidly to trophic restructuring created by diluting seawater. These responses have been observed on hourly to daily timescales (Dolan et al. 2000, Agis et al. 2007) and can be expected to occur during dilution experiment incubations, which are typically performed during a single day. In addition to variable growth rates over the dilution gradient, MZP trophic interactions will vary between dilution treatments. For instance, top-down control of herbivores by larger MZP and microinvertebrates may reduce herbivory rates in low dilutions. Conversely, at higher dilutions primary herbivores are relieved from predatory control, resulting in greater herbivory and decreases in apparent phytoplankton growth. Such complexity is potentially concealed when plotting the response of phytoplankton net growth against the dilution gradient.

Trophic interactions affect both the efficiency of the food web and, potentially, measurements of $\mu$ and $m$. These trophic interactions depend upon the structure of the microbial food web (i.e. the relative abundance of MZP groups). If there are multiple trophic transfers among MZP, a large portion of primary production is lost to respiration. Thus, less primary production is available to metazoans relative to systems with a lower number of trophic transfers. Because the microbial food web structure varies between environments (e.g. Boissonneault-Cellineri et al. 2001, Fileman \& Burkill 2001), the amount of primary production consumed within the microbial food web versus what is available to higher trophic levels can also be expected to differ between environments.

In this study, we supplemented experimental data with a numerical food web model to investigate the response of MZP groups to dilution experiments. At both oligotrophic and eutrophic stations along the Texas coast, parallel dilution experiments were performed in which seawater was screened through either a fine or course mesh to reduce the dominance of intermediate-sized or large grazers, respectively. In our food web model, we considered multiple trophic levels including 1 primary producer, 1 herbivore, and 2 omnivores to examine the effect of trophic complexity and consumer growth on food web efficiency and dilution experiment results. The goal of this work was to examine how trophic interactions within MZP can influence herbivory rate measurements and food web efficiency.

\section{MATERIALS AND METHODS}

Dilution experiments. Eutrophic Corpus Christi Bay (CCB) and the oligotrophic offshore Gulf of Mexico (GOM) were sampled on 7 and 18 June 2001, respectively. The water temperature was $29^{\circ} \mathrm{C}$ at both locations. Salinity was 25 at CCB and 33 at GOM. Detailed site descriptions, sampling procedures, and experimental protocols are reported elsewhere (First et al. 2007). Briefly, seawater was screened through mesh of either 153 or $25 \mu \mathrm{m}$ nominal pore size (hereafter, results from the 2 experiments are distinguished by subscripts indicating the mesh size). Triplicate treatments were set up using ratios of $1.0,0.6,0.3$, and 0.15 mesh-screened water to filter-sterilized $(0.22 \mu \mathrm{m})$ station water. Note that 'high dilutions' refers to treatments with low concentrations of mesh-screened seawater (e.g. 0.15 and 0.3). To equalize the growth conditions of phytoplankton across the dilution gradient, each treatment was enriched with 4 or $8 \mu \mathrm{M}$ $\mathrm{NH}_{4} \mathrm{Cl}$ for CCB and GOM, respectively. Triplicate control treatments of undiluted water without nutrient additions were used to determine the impact of nutrient enrichment on phytoplankton growth. Treatments were incubated in clear polycarbonate bottles in an outdoor, temperature controlled $\left(29 \pm 1^{\circ} \mathrm{C}\right)$ incubator tank with shaded blue Plexiglas for $24 \mathrm{~h}$. In order to keep incubation conditions similar between experiments, we did not attempt to adjust the shading to reflect in situ irradiance at these sites, which was not measured in this study. 
Phytoplankton concentration was measured by collecting phytoplankton on filters, extracting chlorophyll a (chl a), and measuring chl a fluorescence. Phytoplankton relative size distribution was determined by filtering 10 to $300 \mathrm{ml}$ of whole seawater onto 5 and $0.22 \mu \mathrm{m}$ pore size Nuclepore filters to determine the contribution of large (>5 $\mu \mathrm{m}$ ) phytoplankton to the total chl a concentration. Chl a was extracted from the filters in $90 \%$ acetone overnight at $-20^{\circ} \mathrm{C}$ in the dark and measured on a Turner Designs fluorometer (Welschmeyer 1994). The phytoplankton growth rate was determined by filtering 25 to $300 \mathrm{ml}$ of each treatment through $47 \mathrm{~mm}$ diameter $0.22 \mu \mathrm{m}$ pore size Nuclepore membrane filters prior to and after the incubation period; chl a was quantified as described above. Phytoplankton net growth rate $\left(r, \mathrm{~d}^{-1}\right)$ was determined from the logarithmic growth equation

$$
r=\ln \left(\frac{P_{f}}{P_{\mathrm{i}}}\right) \frac{1}{t}
$$

where $P_{\mathrm{i}}$ is the initial and $P_{\mathrm{f}}$ the final chl a concentration, and $t$ is the incubation time (d). A linear regression was used to fit the relationship between $r$ and dilution. The slope of this relationship is phytoplankton grazing mortality rate $(m)$ and the intercept is gross phytoplankton growth rate $(\mu)$. For estimating phytoplankton biomass, a relationship of $23 \mu \mathrm{g}$ C: $\mu \mathrm{g}$ chl a ratio was established by epifluorescence microscope counts of cells with chl a fluorescence.

Biomass, growth rates, and production rates of MZP were determined as described in First et al. (2007). Briefly, 20 to $100 \mathrm{ml}$ of pooled treatment water (preserved in 5\% Lugol's iodine, final conc.) was settled in chambers, and organisms between approximately 15 and $200 \mu \mathrm{m}$ in size were counted either from transects or by scanning the entire chamber $(100$ to $400 \times$ magnification). Cell volumes were determined by measuring linear dimensions via an eyepiece micrometer and converting based on appropriate geometrical figures (Wetzel \& Likens 1991). Cell biomass was determined from published volume-to-carbon relationships (Putt \& Stoecker 1989, Menden-Deuer \& Lessard 2000). All ciliates and dinoflagellates were identified as MZP, and the MZP community was characterized into 3 size classes $(<20$, 20 to 40 , and $>40 \mu \mathrm{m}$ ) based upon the mean equivalent spherical diameter of the group. MZP growth rates were determined from initial and final biomasses using Eq. (1). Both aplastidic and plastidic dinoflagellate taxa were included among MZP, as many plastidic taxa are mixotrophic (Stoecker 1999). Nanoflagellate biomass was determined by epifluorescence microscope counts of $153 \mu \mathrm{m}$ screened water in GOM and CCB experiments for use in the food web model.
Food web model. The food web model used to assess MZP trophic interactions was based on generalized Lotka-Volterra equations that have previously been used to model dilution experiments (Gallegos 1989, Gallegos et al. 1996). In our model, we defined 4 trophic levels consisting of the primary producer and 3 consumers (Fig. 1). The model was designed to investigate herbivore responses to predation pressure and prey abundance; variable MZP response functions were not incorporated. The death rate of the top trophic level $\left(\mathrm{C}_{4}\right)$ was assumed to be zero over the incubation time. Simulations were initialized with the biomass values determined in each experiment (Table 1). The primary herbivores $\left(\mathrm{C}_{2}\right)$ in the model were considered to include both nanoplankton-sized grazers (i.e. nanoflagellates and small ciliates were included in MZP $<20 \mu \mathrm{m})$. The biomass values of the 20 to 40 and $>40 \mu \mathrm{m}$ MZP size classes were used as the initial biomass of the 2 omnivores $\left(\mathrm{C}_{3}\right.$ and $\mathrm{C}_{4}$ ), respectively. Clearance rates $(\mathrm{F})$ and gross efficiencies (b) were defined for each trophic interaction. For example, $\mathrm{F}_{4,2}$ is the clearance rate of $\mathrm{C}_{4}$ on $\mathrm{C}_{2}$. Specific estimates of MZP growth efficiencies are not available for these locations. Therefore, gross growth efficiencies of all grazers were set to $30 \%$ in all models (Straile 1997). The validity of the food web model was tested using a scenario in which the MZP population did not change (i.e. growth efficiencies $=0 \%$ ) and MZP consumed only phytoplankton (i.e. no trophic interactions among MZP). In this case, the dilution technique recovered the assigned $\mu$ and $m$ (data not shown).

The model was used for 4 distinct tasks. First, 4 model variants (Models I to IV) were created, 1 for each of the 4 data sets $\left(\mathrm{CCB}_{153}, \mathrm{CCB}_{25}, \mathrm{GOM}_{153}\right.$, and $\mathrm{GOM}_{25}$, respectively), by fitting $\mu\left(\mathrm{d}^{-1}\right)$ and MZP clear-

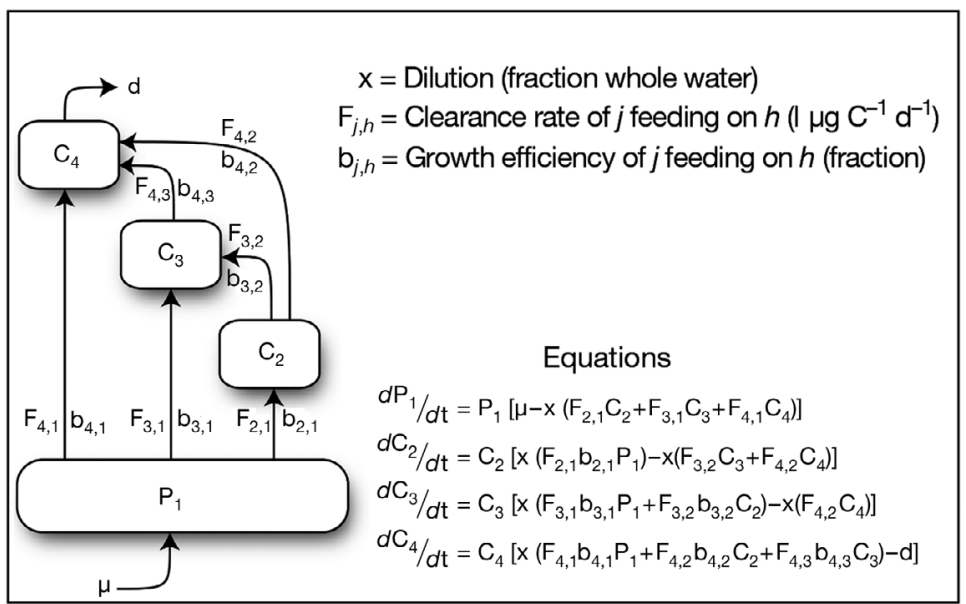

Fig. 1. Conceptual model of the food web in dilution experiment treatments. The concentrations of 4 trophic levels $\left(\mathrm{P}_{1}, \mathrm{C}_{2}, \mathrm{C}_{3}, \mathrm{C}_{4}\right)$ are defined by the interactions in the governing equations. The food web consists of phytoplankton $\left(\mathrm{P}_{1}\right), 1$ herbivore $\left(\mathrm{C}_{2}\right)$, and 2 omnivores $\left(\mathrm{C}_{3}\right.$ and $\left.\mathrm{C}_{4}\right)$. d: death rate, $\mu$ : phytoplankton gross growth rate; $\mathrm{t}$ : incubation time. Subscript numbers $(1,2,3,4)$ identify trophic level 
Table 1. Parameters and simulation outputs for Models I to IV for seawater collected in Corpus Christi Bay, Texas (CCB) and the Gulf of Mexico (GOM) and pre-screened through 153 or $25 \mu \mathrm{m}$ mesh (indicated in subscript). See Fig. 1 for a description of the models and how values were determined. Parameter values are truncated at 2 decimal places. $\mathrm{P}_{1}$ : primary producer, $\mathrm{C}_{2}$ to $\mathrm{C}_{4}$ : consumers,

$F_{j, h}$ : clearance rate of trophic level $j$ feeding on level $h$

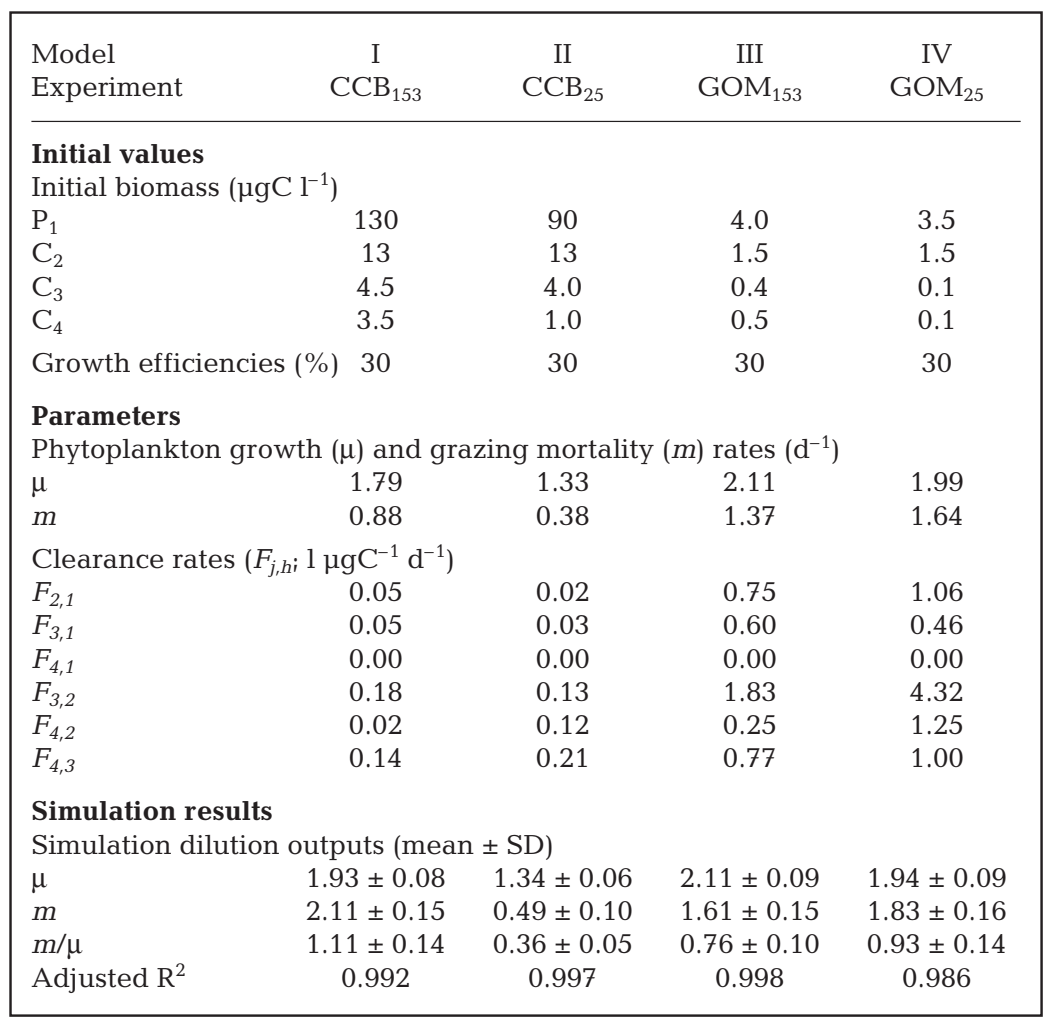

ance rates $\left(1 \mu \mathrm{gC}^{-1} \mathrm{~d}^{-1}\right)$ to these data using a Levenberg-Marquardt optimization algorithm (Press et al. 1988) written in MATLAB (The Mathworks; Table 1). For each model, the community grazing rate was estimated as the summed product of clearance rates and initial biomass of all grazer groups (Fig. 1). Model parameters were estimated sequentially. The model was run with the optimization algorithm allowing only 1 parameter to vary. Using the best fit value for that parameter, the optimization algorithm was repeated, allowing the value of a different parameter to vary. This procedure was repeated until optimized values had been obtained for all parameters. The effect of the order in which parameters were varied was examined using Model I by repeating the above optimization procedure for all permutations of parameter order. The clearance rates generated via the algorithm were within experimentally determined ranges when adjusted for MZP biomass and trophic conditions of the experiment location (Rublee \& Gallegos 1989).

Second, each model was used to simulate a dilution experiment using a Monte Carlo algorithm. This is a stochastic approach that produces a large number of real- izations, allowing for a meaningful statistical analysis of model results. For each model, clearance rates, gross phytoplankton growth rates, and growth efficiencies were randomly selected from normal distributions with a $10 \%$ variation around the parameter values listed in Table 1. The model was then solved numerically using an adaptive step size, 4th order Runge Kutta algorithm (the ode45 routine in MATLAB 6.1). This process was repeated 1000 times for each model, producing 1000 replicate simulations of a dilution experiment. The algorithm performed food web simulations evenly spaced along the dilution gradient (0.05 intervals). A weighted leastsquares linear regression was used to determine $\mu, m$, and adjusted $R^{2}$ values for each simulated experiment (Landry \& Hassett 1982), and the mean and standard deviation of $\mu$ and $m$ were calculated from 1000 replicate simulations. The covariance between $\mu$ and $m$ was determined and used when calculating the standard deviation of $m / \mu$ measurements. We used these model parameters to investigate the phytoplankton growth response when the omnivorous $\operatorname{MZP}\left(\mathrm{C}_{3}\right.$ and $\left.\mathrm{C}_{4}\right)$ are removed from the experiment, as well as the impact of incubation time on model outputs.

Third, a model sensitivity analysis was conducted by varying the model parameters $(p) \pm 10 \%$ of the values in Table 1. Sensitivity $(S)$ was determined as the change in estimated $m$ relative to the baseline values $\left(m_{\mathrm{b}}\right)$ as follows:

$$
S=\frac{p_{\mathrm{b}}}{m_{\mathrm{b}}}\left(\frac{m-m_{\mathrm{b}}}{p-p_{\mathrm{b}}}\right)
$$

where $p_{\mathrm{b}}$ is the baseline value of each parameter (e.g. Miller et al. 2007). Thus, a 10\% change in each parameter will correspond to an $S \%$ change in the grazing rate. The model was determined to be sensitive to a parameter if $S$ is $>10 \%$.

Fourth, MZP growth efficiencies and interactions were investigated in more detail with additional Monte Carlo simulations based on model III. Model III represents conditions at $\mathrm{GOM}_{153}$, where the smallest MZP are expected to be the most important herbivores. Here, MZP were only able to assimilate phytoplankton (i.e. $b_{3,2}, b_{4,2}$ and $b_{4,3}$ were set to zero ). Growth efficiencies of MZP feeding on phytoplankton were varied, and all other parameters were held constant. MZP apparent growth rates in the undiluted water treat- 
ment were calculated by Eq. (1) for each consumer group in each simulated dilution. Mean gross growth efficiency was set to $30 \%$, and the values used in the simulation were randomly selected from a normal distribution within $50 \%$ of the mean.

\section{RESULTS}

\section{Dilution experiments}

Water collected at CCB had a chl a concentration of $5.5 \pm 0.91 \mu \mathrm{g} \mathrm{l}^{-1}$ (mean $\pm \mathrm{SD}$ ) and $38 \%$ of the total chl a was $<5 \mu \mathrm{m}$; GOM had a chl a concentration of $0.2 \pm 0.01 \mu \mathrm{g} \mathrm{l}^{-1}$ and $100 \%$ of the total chl a was $<5 \mu \mathrm{m}$. Phytoplankton net growth in nutrient-amended treatments was significantly greater than that in control treatments in both $\mathrm{CCB}$ experiments and $\mathrm{GOM}_{25}(t$ test, $\mathrm{p}<0.05$ ), but not in $\mathrm{GOM}_{153}$.

The $25 \mu \mathrm{m}$ screening significantly reduced measurements of gross phytoplankton growth rate $(\mu)$ and grazing mortality rate $(m)$ in CCB experiments ( $t$-test, $\mathrm{p}<$ 0.05) (Table 2). Although $\mu$ and $m$ were significantly different, fine-mesh screening significantly altered $r$ only in undiluted water $\left(-0.4 \mathrm{~d}^{-1}\right.$ for $\mathrm{CCB}_{153}$ vs. $0.8 \mathrm{~d}^{-1}$ $\mathrm{CCB}_{25}$, ANOVA, $\mathrm{p}<0.05$ ) (Fig. 2). Therefore, the large difference in $r$ in undiluted water changed the system output from a slight phytoplankton net loss $(m / \mu>1$ in $\left.\mathrm{CCB}_{153}\right)$ to a net gain $\left(\mathrm{m} / \mu<1\right.$ in $\left.\mathrm{CCB}_{25}\right)$. In contrast, $\mu$ and $m$ were not significantly different between the 2 size fractions in the GOM experiments ( $t$-test, $p$ > 0.05). The phytoplankton response curve in $\mathrm{GOM}_{25}$ was distinctly non-linear. This difference can be seen by the lower adjusted $\mathrm{R}^{2}$ values relative to $\mathrm{GOM}_{153}$ (Table 2) and the general curve shape of $\mathrm{GOM}_{25}$ (Fig. 2).

The response of MZP to dilution gradients was measured by MZP net growth rates over the incubation period. Ciliate, dinoflagellate, and total MZP responses varied in some cases depending on initial screening size. In the CCB experiments for example, these groups responded oppositely in the 0.3 treatment (Fig. 3). Categorizing MZP by cell size (rather than as

Table 2. Results of linear regression analysis of size-fraction dilution experiments in CCB and GOM, with initial screening through either 153 or $25 \mu \mathrm{m}$ mesh (denoted by subscript). Values reported are gross phytoplankton growth rate $(\mu)$ and grazing $(m)\left(\mathrm{d}^{-1}\right.$, mean $\left.\pm \mathrm{SD}\right)$ and adjusted regression coefficients $\left(\mathrm{R}^{2}\right) ; \mathrm{p}<0.01$ in all cases

\begin{tabular}{|lcccc|}
\hline & $\mathrm{CCB}_{153}$ & $\mathrm{CCB}_{25}$ & $\mathrm{GOM}_{153}$ & $\mathrm{GOM}_{25}$ \\
\hline$\mu$ & $1.97 \pm 0.54$ & $1.39 \pm 0.22$ & $2.11 \pm 0.38$ & $1.92 \pm 0.92$ \\
$m$ & $2.16 \pm 0.88$ & $0.57 \pm 0.36$ & $1.58 \pm 0.63$ & $1.73 \pm 1.52$ \\
$\mathrm{~m} / \mu$ & $1.10 \pm 0.54$ & $0.41 \pm 0.65$ & $0.75 \pm .44$ & $0.90 \pm 1.01$ \\
$\mathrm{R}^{2}$ & 0.86 & 0.72 & 0.87 & 0.57 \\
\hline
\end{tabular}

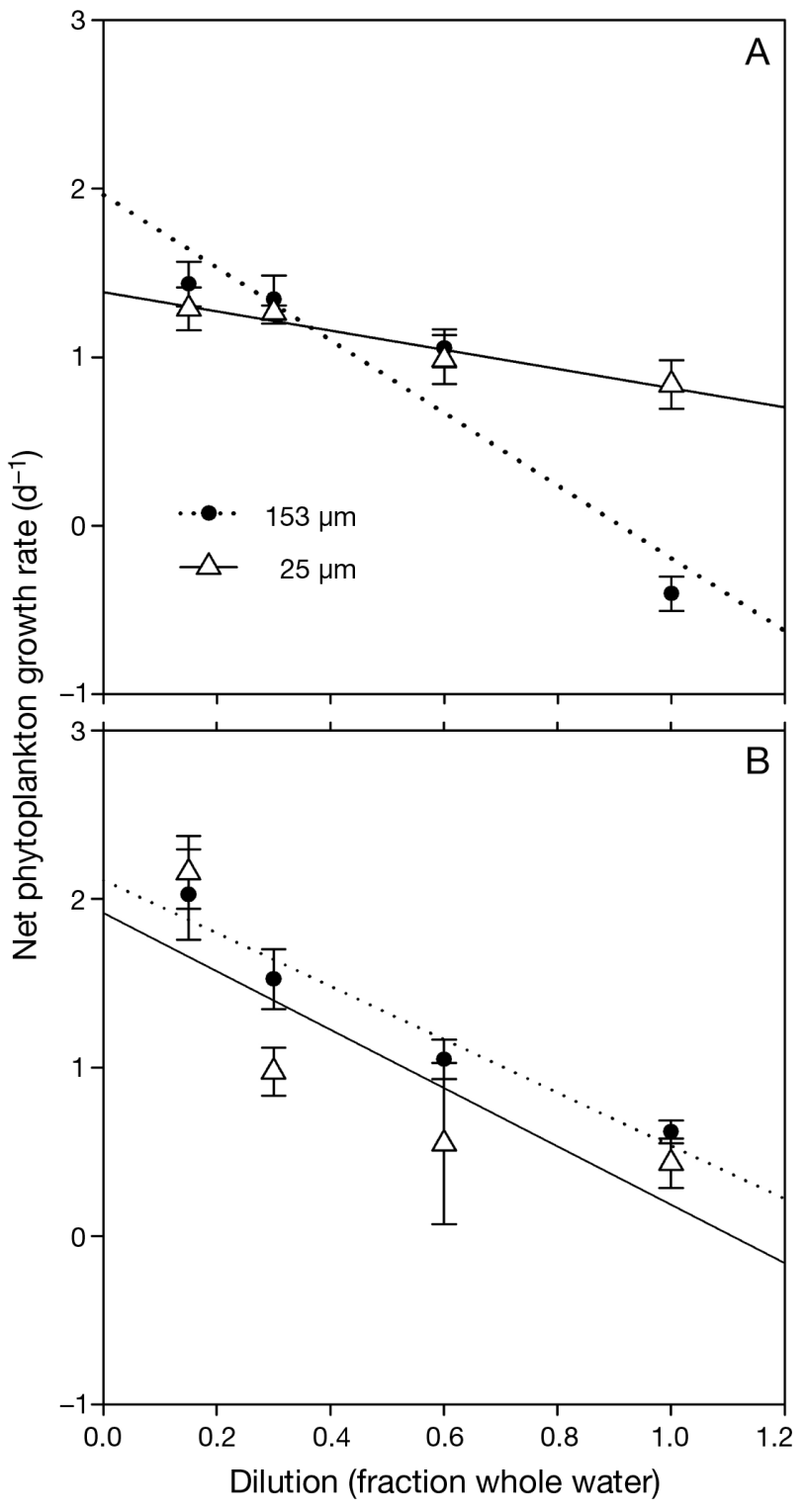

Fig. 2. (A) Corpus Christi Bay (CCB) and (B) Gulf of Mexico (GOM) size-fractionation dilution experiments. Phytoplankton net growth is plotted for serial dilution experiments with seawater initially screened though either 153 or $25 \mu \mathrm{m}$ mesh. Points are mean \pm SD. Regression data are shown in Table 2

ciliates or dinoflagellates) revealed different patterns of net growth in the dilution experiments (Fig. 4). In $\mathrm{CCB}_{153}$ undiluted water, the intermediate size range (20 to $40 \mu \mathrm{m}$ ) showed highest net growth rates, whereas the smallest $(<20 \mu \mathrm{m})$ and largest $(>40 \mu \mathrm{m})$ groups had higher growth rates in $\mathrm{CCB}_{25}$ (Fig. 4). In both 0.3 and 0.15 dilution treatments, the response of the intermediate-sized group was opposite to that of the largest and smallest MZP. For example, in the $\mathrm{CCB}_{153}$ experiment, the intermediate-sized MZP declined, while the other size groups increased. The 

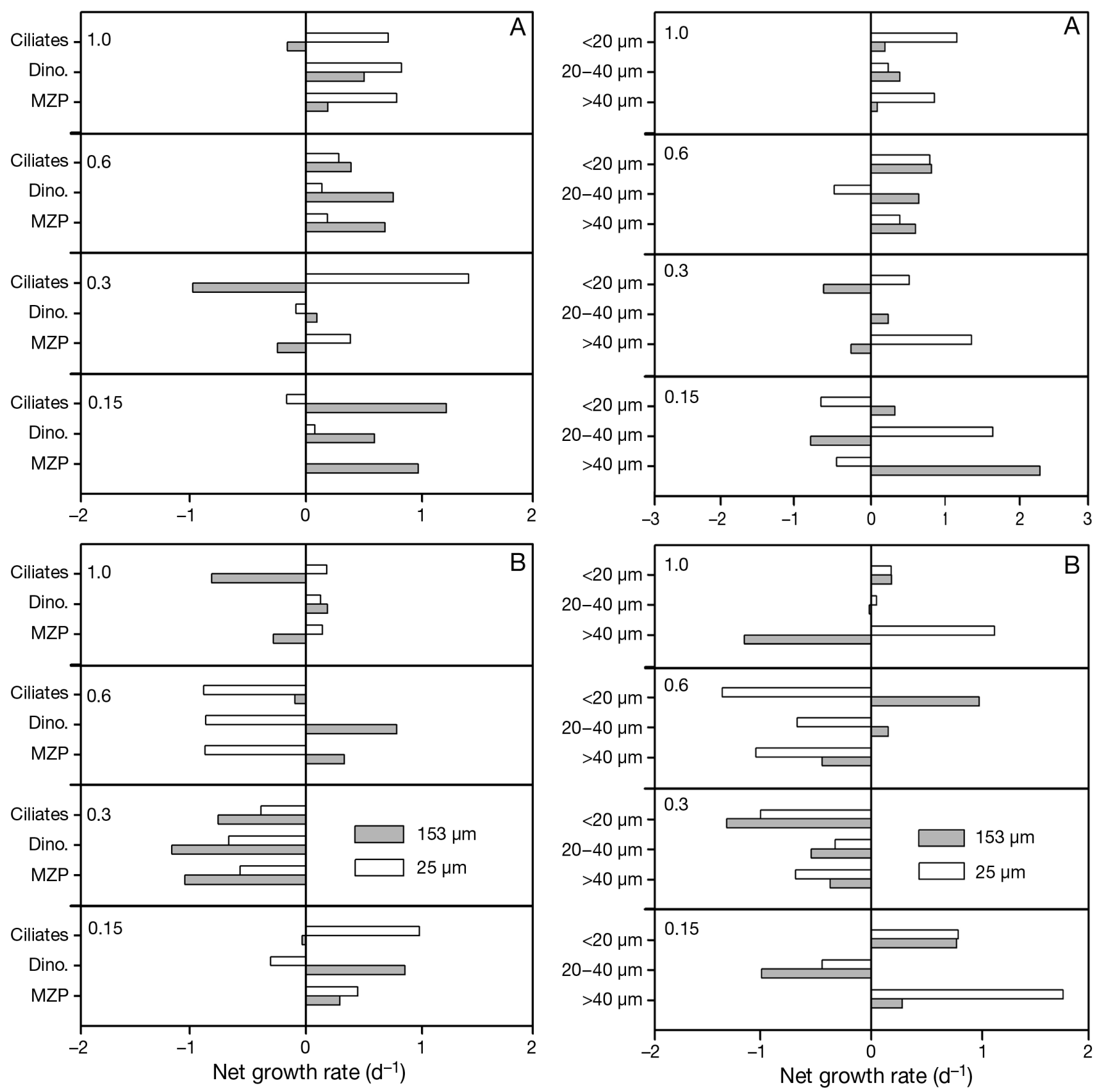

Fig. 3. Microzooplankton (MZP) growth rates $\left(\mathrm{d}^{-1}\right)$ of ciliates, dinoflagellates (Dino.), and total MZP in all dilution treatments in the 2 size-fractionation experiments in (A) CCB and (B) GOM. The dilution treatments are identified by the fraction of screened seawater $(1.0,0.6,0.3,0.15)$

Fig. 4. MZP growth rates $\left(\mathrm{d}^{-1}\right)$ in all dilution treatments in the 2 size-fractionation experiments in (A) CCB and (B) GOM. Equivalent spherical diameter (ESD) was used to categorize MZP into the following size groups: $<20,20$ to 40 , and $>40 \mu \mathrm{m}$. The dilution treatments are identified by the fraction of screened seawater $(1.0,0.6,0.3,0.15)$

opposite pattern was observed in the 0.15 dilution. The alternating growth and production patterns were observed in the 2 highest dilutions at $\mathrm{CCB}_{25}$ but the pattern was reversed (i.e. growth of a size group in $\mathrm{CCB}_{153}$ corresponded to a decline of that group in $\mathrm{CCB}_{25}$ ). In GOM, the MZP response to high dilutions

(0.3 and 0.15) did not differ between the 2 size-fraction experiments. However, in the 1.0 and 0.6 dilution treatments, the MZP growth patterns differed. Notably, the largest MZP declined in the $153 \mu \mathrm{m}$ fraction, but not in the $25 \mu \mathrm{m}$ fraction. Also, a $<20 \mu \mathrm{m}$ MZP increased in $\mathrm{GOM}_{153}$, but declined in $\mathrm{GOM}_{25}$ (Fig. 4). 


\section{Food web model simulations}

We created 4 parameterizations of the food web model (Models I to IV), each parameterized using data from one of the dilution experiments. All 4 models were sensitive to the initial phytoplankton biomass and $\mu_{i}$ Models II to IV were also sensitive to the initial biomass of $\mathrm{C}_{2}$, the primary herbivore (Fig. 5). The clearance rates of the $\mathrm{C}_{2}$ also caused large variations in model outputs, especially in Models III and IV, whereas Models I and II were sensitive to clearance rates and growth efficiencies of $\mathrm{C}_{3}$. All models showed low sensitivity to the clearance rates and growth efficiencies of $\mathrm{C}_{4}$, the top MZP.
The order in which parameters were optimized did not affect the final values for the parameters to which the model was most sensitive. For example, Model I showed the highest sensitivity to initial $\mu$ and $F_{3,1}$ values. The algorithm chose parameters that were within $10 \%$ of the mean value in both cases. Other parameters (such as $\mathrm{F}_{4,2}$, which varied by $>100 \%$ of the mean) were highly variable depending upon the fitting order. However, the model was not sensitive to these initial values.

The correlation coefficients between the model and data were $0.90,0.73,0.90$, and 0.69 for Models I to IV, respectively. The Monte Carlo method produced 1000 replicate data points for each of the 21 dilution concen-
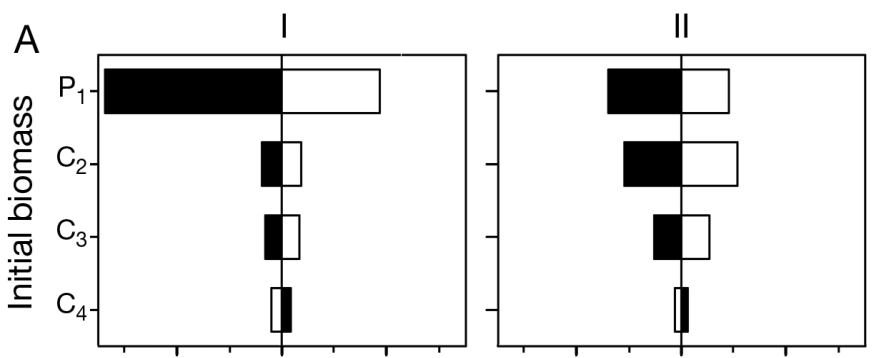

B

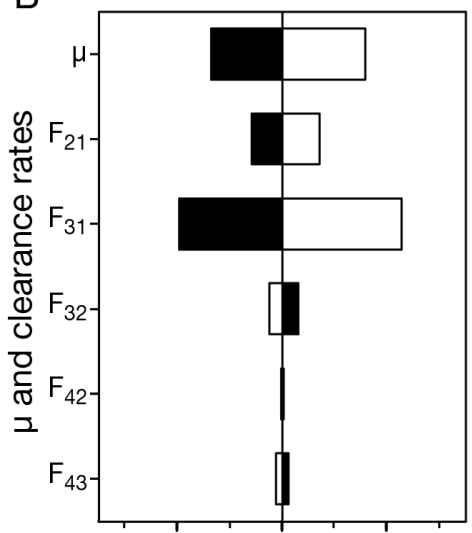

C

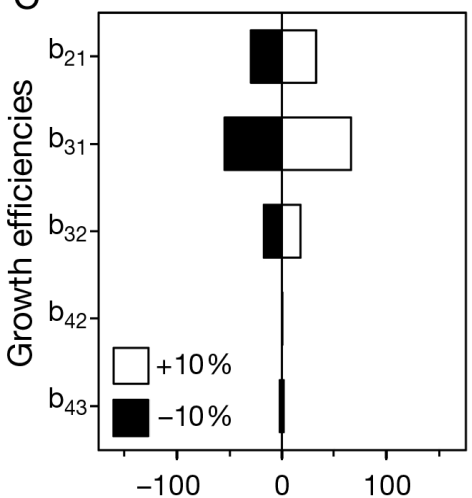

II

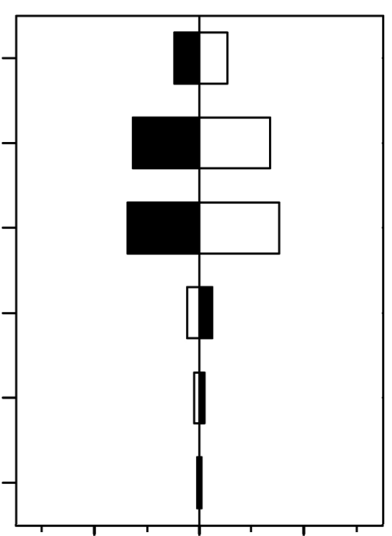

III
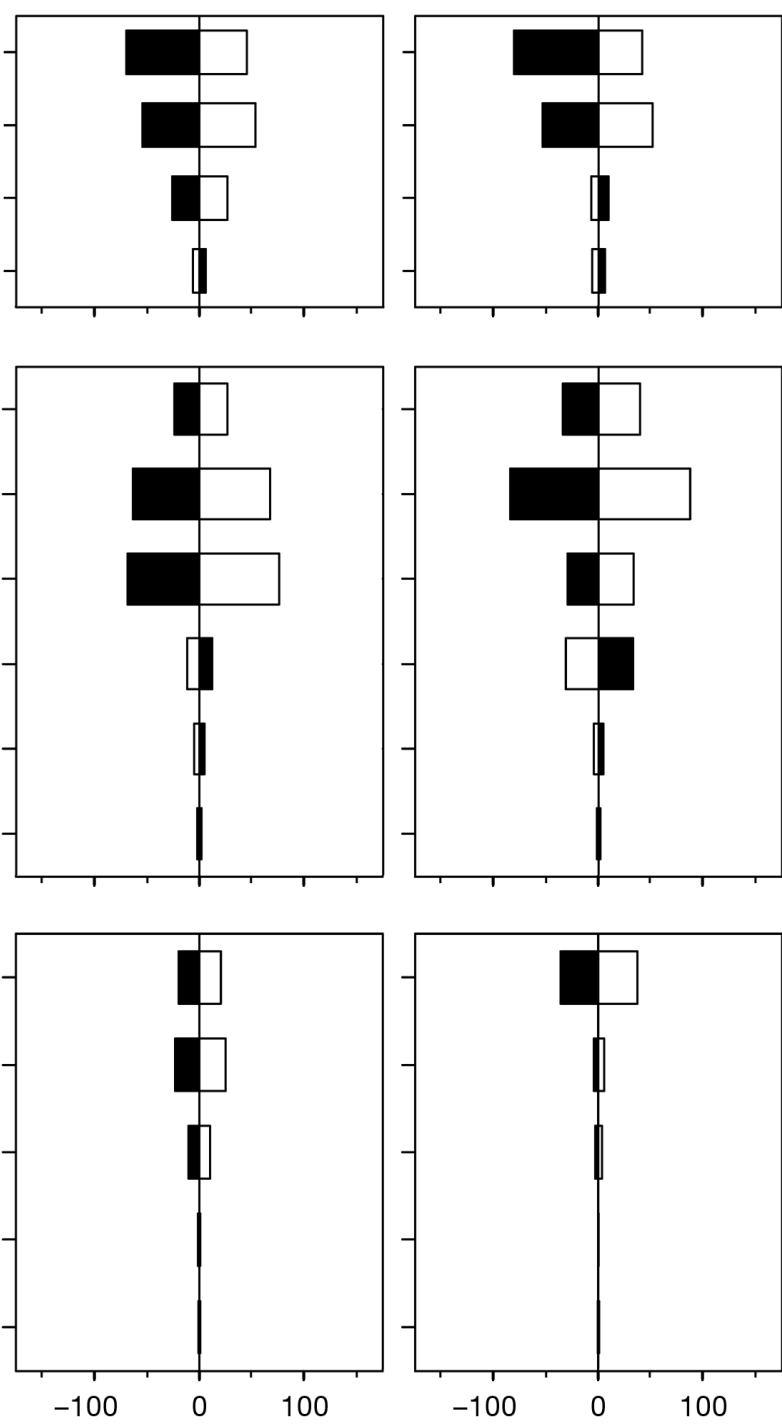
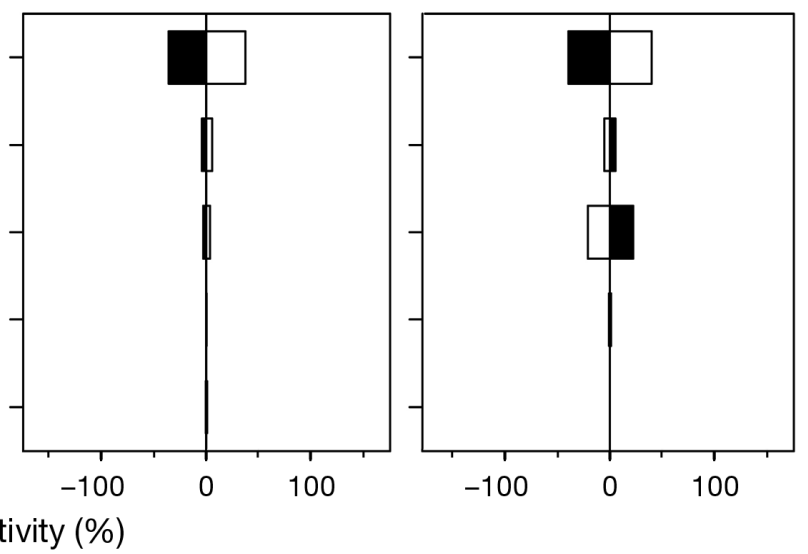

Fig. 5. Sensitivity analysis of Models I to IV. Bars show the percentage change in the response variable, phytoplankton grazing mortality rate $(\mathrm{m})$, to a $10 \%$ increase or decrease in the model parameter. (A) Initial biomass values, (B) phytoplankton growth and MZP clearance rates, and (C) growth efficiencies. Parameters are defined in Fig. 1 


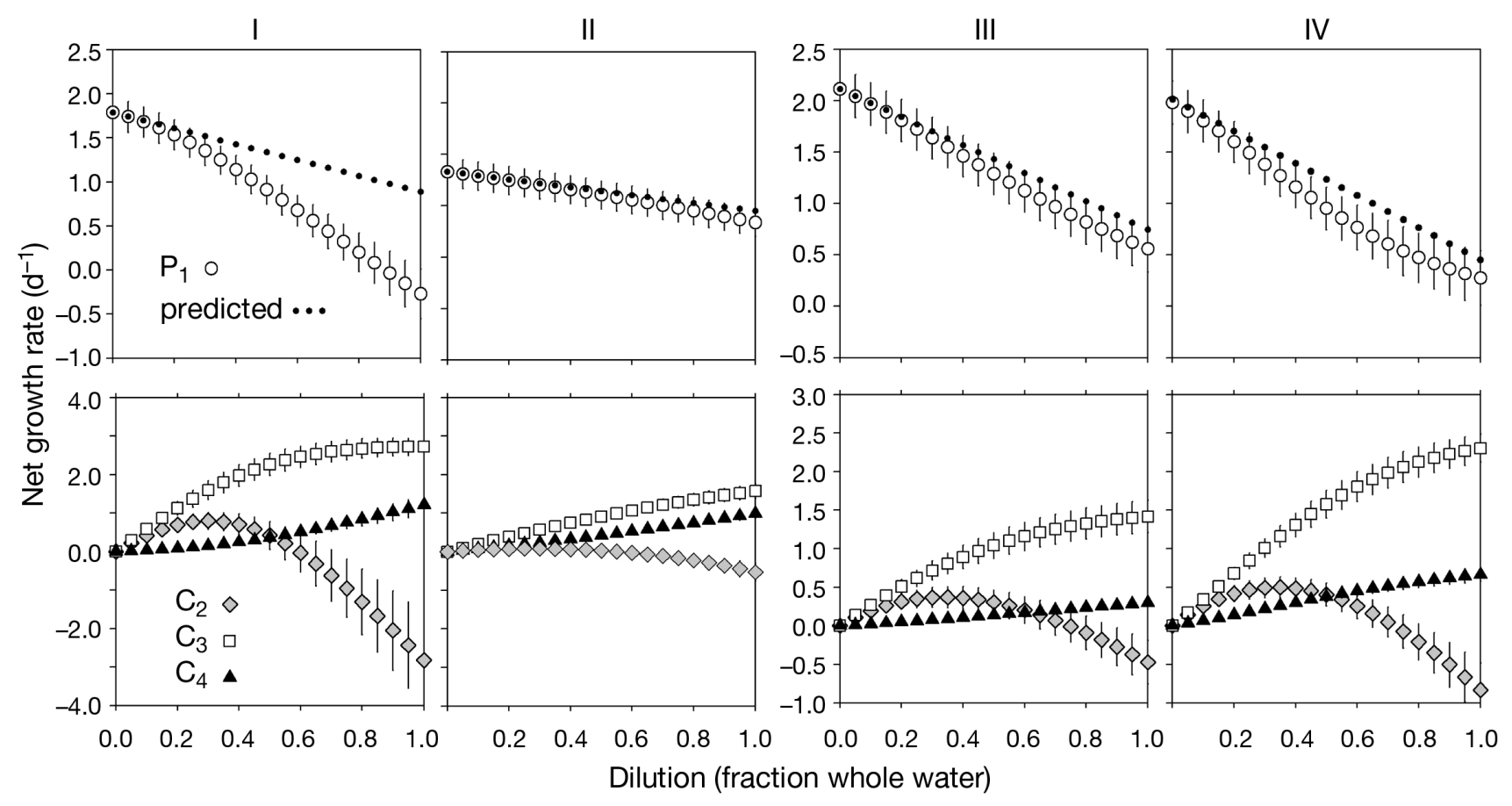

Fig. 6. Dilution plots based on models I to IV (Table 1). Top plots indicate net phytoplankton growth rate $(\mathrm{O}$, mean \pm SD) with the predicted line based upon the assigned $\mu$ and $m$ (dotted). Bottom plots show net growth rates of the 3 groups of MZP consumers. Points show the mean $\pm \mathrm{SD}$ value of simulation results $(\mathrm{N}=1000)$

trations (Fig. 6). Linear regression analysis based upon all 21000 data points resulted in an overestimation of $m$ in all models (Table 1). Phytoplankton grazing mortality rate estimates were 1.1 to almost $2.4 \times$ the actual rates. However, estimates of $\mu$ were within $10 \%$ of the assigned values listed in Table 1 . The growth response of MZP varied between models (Fig. 6). In undiluted water, the change in concentration over the incubation period (measured here by the net growth rate) was high in some cases. At low dilutions, $\mathrm{C}_{3}$ showed the highest growth rate $\left(>2 \mathrm{~d}^{-1}\right.$ in Model I), whereas $\mathrm{C}_{2}$ had negative growth rates in all models.

Grazing rate estimates were more responsive to changes in the growth of $\mathrm{C}_{2}$ than $\mu$ as determined by the fit of exponential growth curves based on Model III (Fig. 7). The changes in the concentrations of $\mathrm{C}_{3}$ and $\mathrm{C}_{4}$ showed no strong relationship with $\mu$ and $m_{\text {; therefore, }}$ these plots are not shown. These groups have their maximal clearance rates on intermediate trophic levels (Table 1). This top-down control was apparent when the net growth rates of phytoplankton and $\mathrm{C}_{2}$ are shown with higher trophic levels removed. The results of this analysis, which investigates the presence of trophic cascades in all 4 models by sequentially removing MZP groups, are shown in Fig. 8. With either all 3 MZP or just $C_{2}$ and $C_{3}$, the net growth rate of $C_{2}$ was negative in all 4 models. Net $\mu$ values in the undiluted treatments were higher in Models I, III, and IV when higher trophic levels (i.e. $\mathrm{C}_{3}$ and $\mathrm{C}_{4}$ ) were included. With the exception of Model II, all food webs show that $\mathrm{C}_{2}$ is partially controlled by higher trophic levels of MZP. The removal of higher trophic levels increases $\mathrm{C}_{2}$ growth and, in turn, reduces phytoplankton growth in undiluted water (Fig. 8).

Estimates of $\mu$ and $m$ are also affected by incubation time. Note that $\mu$ and $m$ rates are reported per day $\left(\mathrm{d}^{-1}\right)$ to allow for comparisons between these incubations. The shortest incubation time $(0.5 \mathrm{~d})$ yielded values of $m\left(d^{-1}\right)$ and $m / \mu$ closest to the assigned values (Table 3). However, the $1 \mathrm{~d}$ incubation best recovered the assigned $\mu$ of $2.11 \mathrm{~d}^{-1}$. While the shortest incubation time best recovered the assigned herbivory rate, the secondary consumer $\left(\mathrm{C}_{3}\right)$ had high net growth rates even over short incubation periods (Fig. 9). Longer incubation times also led to more complex growth patterns of MZP. In the case of the $1.5 \mathrm{~d}$ incubation, the shape of the curve appears as what has been interpreted as a saturated feeding response (Gallegos 1989) (Fig. 9b).

\section{DISCUSSION}

The advantage of serial dilution experiments is that, with relatively little manipulation, they generate paired estimates of phytoplankton growth and grazing 


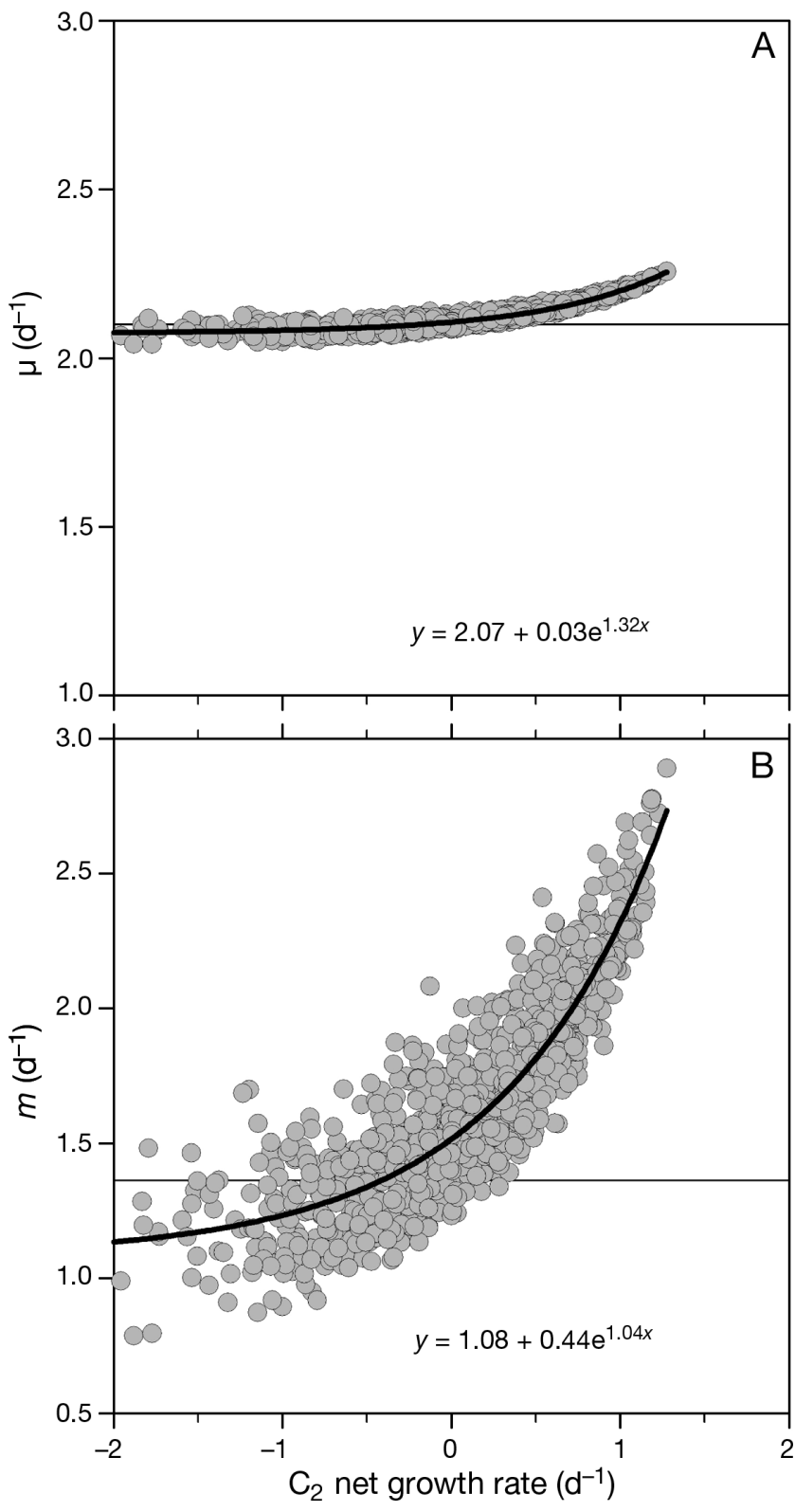

Fig. 7. Dilution results based upon model III. The $x$-axis is the net growth rate of $\mathrm{C}_{2}$ in undiluted treatments plotted against (A) $\mu\left(\mathrm{d}^{-1}\right)$ and (B) $m\left(\mathrm{~d}^{-1}\right)$ on the $y$-axes

mortality rates. Additionally, the ratio of these 2 rates $(\mathrm{m} / \mu)$ indicates the portion of phytoplankton growth consumed by microherbivores. This ratio has been used to compare microbial dynamics across marine systems (Calbet \& Landry 2004). The critical reviews (e.g. Gallegos 1989, Evans \& Paranjape 1992) and modifications (Landry et al. 1995, Gallegos et al. 1996) of the dilution technique reflect its widespread use and the importance in constraining the amount of primary production consumed in marine pelagic environments. In this study, we examined how the microbial food web
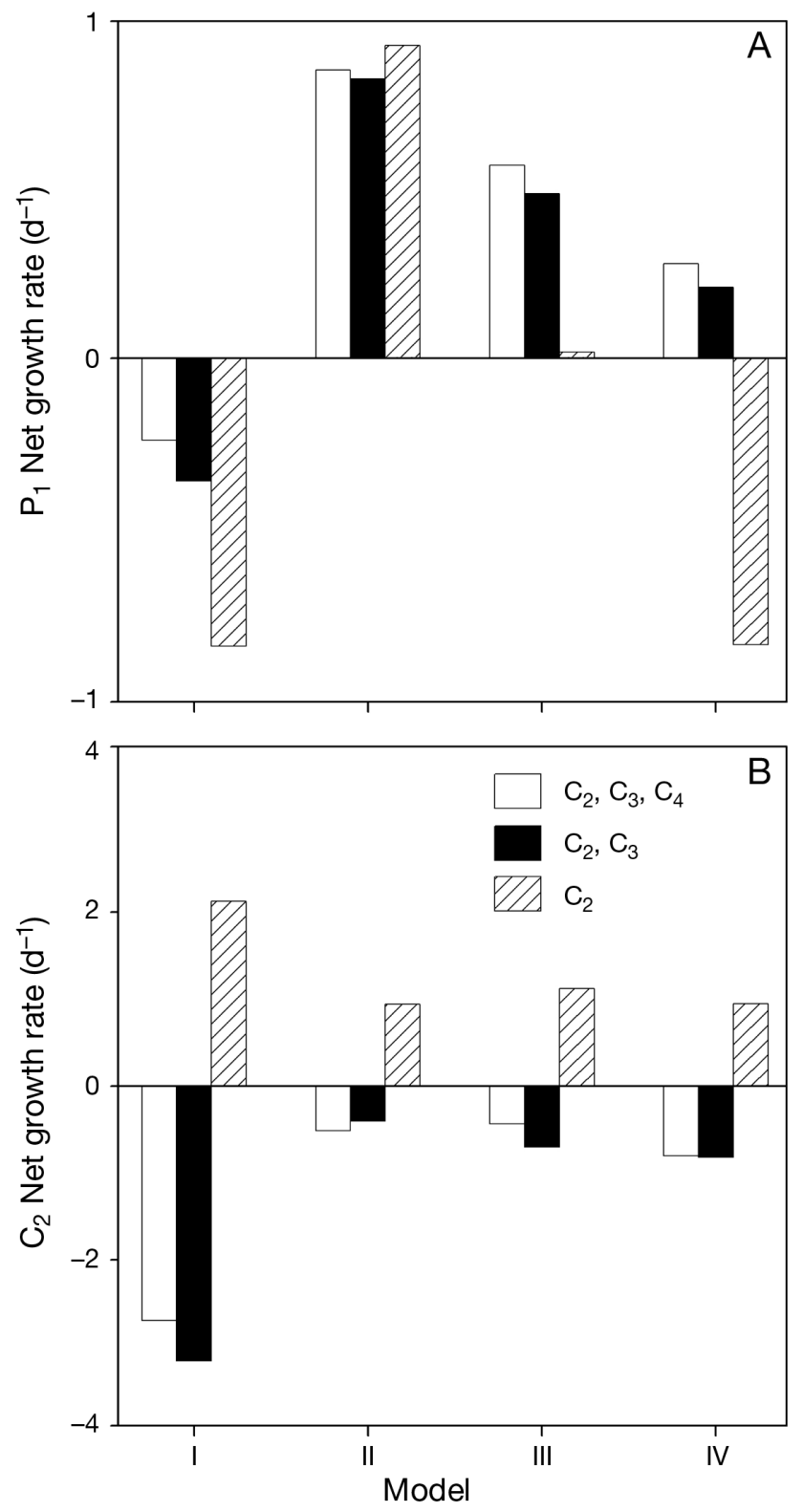

Fig. 8. Model generated rates of (A) $P_{1}$ net growth and (B) $C_{2}$ net growth in undiluted treatment (1.0 whole water). The model parameters were the same as in Table 1. Models were run with: $3 \mathrm{MZP}\left(\mathrm{C}_{2}, \mathrm{C}_{3}\right.$, and $\left.\mathrm{C}_{4}\right)$ included; the top MZP group removed $\left(\mathrm{C}_{2}, \mathrm{C}_{3}\right)$; and the top 2 MZP groups removed $\left(\mathrm{C}_{2}\right)$

at 2 contrasting locations responded to the dilution gradient when the assemblages of MZP were artificially restructured by screening. MZP contain many disparate groups of phagotrophic protists, and these constituent groups are expected to respond differently to the dilution gradient.

Differences in MZP community structure imply the existence of various trophic pathways and food web efficiencies. For example, ciliates and flagellates consume prey that are much smaller (proportional to their 
Table 3. Regression analysis results of simulations based upon model III with different incubation times. Assigned $\mu$ and $m$ are 2.11 and $1.37 \mathrm{~d}^{-1}$, respectively $(m / \mu=0.65)$. Values shown are $\mu$ and $m\left(\mathrm{~d}^{-1}\right), m / \mu$ (no units), and adjusted regression coefficient $\left(\mathrm{R}^{2}\right)$ based upon 1000 simulations (mean \pm $\mathrm{SD}$ ). Plots for $1 \mathrm{~d}$ incubation times are shown in Fig. 6. Example plots with 0.5 and $1.5 \mathrm{~d}$ incubation times are shown in Fig. 9

\begin{tabular}{|cccccc|}
\hline \multicolumn{5}{c|}{ Incubation time (d) } \\
& 0.5 & 0.75 & 1.0 & 1.25 & 1.5 \\
\hline$\mu$ & $2.13 \pm 0.09$ & $2.12 \pm 0.09$ & $2.11 \pm 0.09$ & $2.08 \pm 0.08$ & $2.01 \pm 0.08$ \\
$m$ & $1.47 \pm 0.16$ & $1.54 \pm 0.16$ & $1.61 \pm 0.15$ & $1.68 \pm 0.14$ & $1.72 \pm 0.13$ \\
$m / \mu$ & $0.69 \pm 0.10$ & $0.73 \pm .10$ & $0.76 \pm 0.10$ & $0.80 \pm 0.09$ & $0.86 \pm 0.08$ \\
$\mathrm{R}^{2}$ & 1.00 & 1.00 & 1.00 & 0.99 & 0.98 \\
\hline
\end{tabular}

along the dilution gradient when predator-prey encounters become too rare to sustain the predator or to control the prey. For example, at $\mathrm{CCB}_{153}$, ciliates showed the highest net growth rate at the highest dilution. Herbivorous ciliates, released from predation pressure in moderately high dilutions, will limit the phytoplankton net growth in these treatments. Likewise, increases in dinoflagellate biomass (observed in low dilutions in both CCB size fractions) could limit the grazing impact of herbivorous MZP.

In a complex food web, each dilution
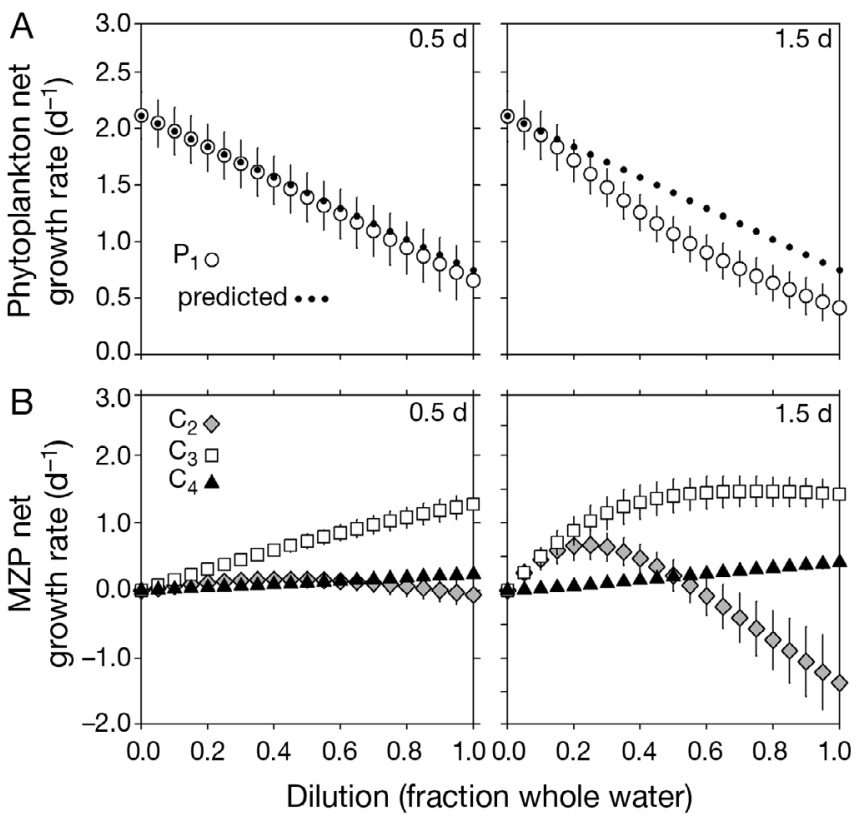

Fig. 9. Dilution plots based on model III, showing (A) phytoplankton and (B) MZP net growth rates along the dilution gradient at incubation periods of 0.5 and $1.5 \mathrm{~d}$. Plots are as described in Fig. 6. The results of the linear regressions are reported in Table 3

body size) than dinoflagellates (Hansen et al. 1994). Thus, an abundance of small and intermediate-sized ciliates can lead to higher grazing mortality of picoplankton. Dinoflagellates consume prey equal to or greater than their body size (Naustvoll 2000), and several dinoflagellate taxa observed at CCB are capable of ingesting larger MZP (Stoecker 1999). Consequently, a high relative abundance of dinoflagellates can lead to predation of intermediate-sized and large MZP.

\section{MZP responses to the dilution gradient}

Serial dilutions create a resource gradient for MZP. Trophic links within the MZP are sequentially broken treatment will select for the dominant trophic pathways. The resulting phytoplankton net growth rate measurements may yield patterns that appear similar to those predicted by MZP feeding responses. In the open GOM, phytoplankton growth was suppressed in the small size fraction $\left(\mathrm{GOM}_{25}\right)$ relative to the large fraction $\left(\mathrm{GOM}_{153}\right)$ in all treatments except the highest dilution ( 0.15 fraction whole water). The phytoplankton response along the curve may indicate saturated feeding (i.e. above a certain prey density, the MZP ingestion rate remains constant). This prey concentration at which herbivores are saturated can be only a fraction of the ambient prey density (Gallegos 1989). However, it seems unlikely that herbivorous MZP (with high intrinsic rates) could be prey saturatedespecially in oligotrophic waters such as in the open GOM. Instead, this response may be due to suppression of the smallest MZP size category $(<20 \mu \mathrm{m})$ in the 0.6 and 0.3 fraction whole water in $\mathrm{GOM}_{25}$. In this case, a trophic cascade (where larger MZP graze small MZP, which, in turn, reduce their grazing control on nanograzers) may result in the low net $\mu$ values (e.g. Carrias et al. 2001).

Non-linear phytoplankton growth responses to the predator gradient (i.e. dilution) have been explained by MZP feeding responses to phytoplankton (Moigis 2006). The occurrence of feeding responses is well established for both metazoan (e.g. Sarnelle 2003) and protistan (e.g. Waterhouse \& Welschmeyer 1995) populations. However, the appearance of non-linear phytoplankton responses to dilution gradients may represent trophic interactions among MZP rather than feeding responses. The food web models demonstrate that changes in the MZP concentrations (measured by MZP net growth rates) produce non-linear phytoplankton responses to the dilution gradients. These non-linear responses were caused by trophic interactions among MZP rather than feeding responses due to the decreasing abundance of phytoplankton along the dilution gradient. For example, the top-down control by higher trophic levels suppressed the growth of the 
primary herbivores $\left(\mathrm{C}_{2}\right)$ in model simulations. Once released from this top-down pressure, $\mathrm{C}_{2}$ was able to grow, and phytoplankton growth was reduced in most models. The food web model reflects the experimental and observational studies showing that interactions between primary and secondary consumers cascade to drive the dynamics of primary producers (e.g. Jürgens et al. 1996, Reckermann \& Veldhuis 1997).

\section{MZP trophodynamics and food web efficiency}

Increased trophic interactions among MZP will reduce the amount of primary production available to metazoan consumers. At each trophic transfer, a large portion of the organic matter ingested is not converted into biomass. The gross growth efficiency (i.e. biomass produced per biomass consumed) indicates the portion of ingested biomass not lost to respiration or egestion. The gross growth efficiency used in this study (30\%) is similar to what has been found for a range of aquatic herbivores (Straile 1997). Gross growth efficiency may also depend upon physical characteristics of the prey, such as body size and nutritional composition. For example, small bacterivorous ciliates can have a much higher gross growth efficiency than large omnivorous ciliates feeding upon picoplanktonic prey (Ohman \& Snyder 1991).

Transfer of primary production to the metazoan food web depends upon the relative composition of MZP. For example, larger MZP can be more readily ingested by copepods (Liu et al. 2005). Also, ciliates are consumed by copepods at high rates in marine environments (Calbet \& Saiz 2005, Schnetzer \& Caron 2005). If large MZP (i.e. $>40 \mu \mathrm{m}$ equivalent spherical diameter) are the organisms most efficiently consumed by metazoans, then the efficiency of transfer to higher trophic levels will depend upon the prey source of these MZP. If these large MZP are herbivores, then the microbial food web will be fairly efficient in transferring primary production to higher levels. Conversely, if multiple trophic transfers occur within the microbial food web, a smaller portion of the original production will be available to metazoan consumers. Because the entire phytoplankton community at the oligotrophic GOM station was $<5 \mu \mathrm{m}$, large MZP may preferentially consume small and intermediate-sized grazers. Other factors, such as the prevalence of mixotrophic MZP, will also affect the carbon available to metazoans in these 2 contrasting environments. Some ciliates that are capable of mixotrophic growth (e.g. Laboea sp.; Sanders 1995, Dolan \& Perez 2000) were abundant at the GOM station. Carbon fixation by phagotrophic protists will result in more energy being available for higher trophic levels in the microbial food web.

\section{Assumptions of the food web model}

Our food web model did not incorporate feeding response functions, which are commonly used in microbial food web models (Gallegos 1989, Moigis 2006). Changes in MZP clearance rates with prey concentrations (i.e. feeding responses) also yield non-linear phytoplankton growth curves in simulated food webs (Moigis 2006). Our model demonstrated the occurrence of non-linear phytoplankton growth curves due exclusively to MZP growth and trophic interactions. Feeding responses are likely to play a role under conditions of abundance or scarcity of phytoplankton. For example, high abundances of the brown tide-forming alga limit MZP grazing, although this may be due to higher concentrations of inhibitory chemicals during blooms (Buskey \& Hyatt 1995). In some cases, MZP are able to consume phytoplankton rapidly during bloom conditions (Strom et al. 2001), indicating that MZP grazing may not be reduced at high prey concentrations. A practical reason for not incorporating feeding responses into this model is that information on MZP feeding responses (which likely depend upon specific characteristics of both prey and predator taxa, as well as ambient temperature) is not readily available. An averaged feeding response of the entire community is also inappropriate considering the trophic diversity incorporated into the MZP grouping.

In our food web model, we considered only 1 group of phytoplankton. The implication of multiple groups is that some phytoplankton will be functionally unavailable to certain grazers. For example, picophytoplankton may not be grazed by the largest herbivores. Considering only 1 group of phytoplankton is less reflective of natural systems where phytoplankton span a large size range. Also, delineating the MZP into 3 discrete groups is an oversimplification of real world dynamics. For example, we did not include the possibility that intermediate or upper trophic levels (i.e. $\mathrm{C}_{3}$ or $\mathrm{C}_{4}$ ) may ingest organisms on the same or higher trophic level (e.g. Hansen \& Calado 1999), nor did our model include the possibility for mixotrophic growth (Stoecker 1999). Although an oversimplification, this model demonstrates the potential role of MZP growth and trophodynamics on food web efficiency and the measurements of $\mu$ and $m$. A greater understanding of the interactions within this diverse size group will lead to more sophisticated numerical models and predictions of carbon flows through the microbial food web.

\section{Design considerations for serial dilution experiments}

The dilution technique yielded accurate estimates of $\mu$ in most model simulations. However, including MZP 
growth and trophic interactions in the models yielded overestimates of grazing rates in simulated serial dilution experiments for all models. Another approach to estimating MZP grazing is via a 2-point dilution, which compares phytoplankton growth between undiluted and highly diluted water (e.g. $5 \%$ seawater; Landry 1993). It assumes that herbivore impact in highly diluted water is insignificant (i.e. not statistically different from zero). This simplified technique eliminates uncertainties related to differential MZP growth across the dilution gradient and yields conservative estimates of community herbivory rates. However, the 2-point approach does not reveal MZP dynamics that can be evident from non-linear phytoplankton growth curves; these non-linear dynamics should be examined if we are to improve our understanding of complex microbial food web interactions.

Comparisons of $\mu$ and $m$ across systems may be complicated by slight differences in the methods employed. For example, in the present study we did not attempt to recreate in situ irradiance at each location. Phytoplankton adapted to lower light levels in turbid waters may respond differently under these conditions. Nutrient additions stimulated phytoplankton growth in all dilutions, but it is likely that different phytoplankton assemblages will respond differently to nutrient amendments. For example, high nutrients may lead to higher nutritional quality of the phytoplankton rather than higher growth rates. Screening size can also influence the outcome of dilution experiments. The initial screening size (or stress caused by screening) truncates the food web and sets up cascading controls on primary herbivores. In these experiments, we used considerably different mesh sizes to screen seawater. However, even small differences in initial screening mesh size can lead to different dominant trophic pathways.

Variation in incubation times can also lead to different experimental outcomes as interactions between MZP have a longer time to evolve. For example, the greatest changes in nanozooplankton are observed during the last portion of a day-long incubation period (Agis et al. 2007). Consequently, differences between, for example, a $24 \mathrm{~h}$ and a $30 \mathrm{~h}$ incubation period may be significant. Shorter incubation periods may limit the effect of MZP growth and trophic interactions on the experimental outcomes. However, fluctuations in phytoplankton production over the course of a day will cause complications when selecting the light period at which to incubate the treatments (e.g. including highlight or no-light periods). Additionally, short incubation times may not be appropriate in low-temperature environments, where phytoplankton biomass can change at slower rates. Sampling periodically during the incubation period (especially toward the end of the incubation) can reveal the incubation time when MZP growth and interactions become significant enough to lead to overestimates of the in situ grazing rate.

In summary, even the simplified model representation of MZP growth and trophic interactions presented here illustrates the complexity of the microbial food web and cautions from the interpretation of dilution experiment results based exclusively on the response of phytoplankton. These models demonstrate the potential for herbivore growth and interactions to shape the outcomes of dilution experiments. In addition to measuring phytoplankton growth and grazing mortality, serial dilution experiments may be the most effective approach to delineating trophic links among MZP. Further work in plotting interactions and growth efficiencies, and constraining the regulatory forces in the microbial food web promises a greater understanding of energy flow in aquatic systems.

Acknowledgements. The University of Akron Graduate Program and the Nancy Lee and Perry Bass Endowed Chair funding to the University of Texas at Austin Marine Science Institute (UTMSI) supported the field and lab work portions of this manuscript. W. S. Gardner and M. J. McCarthy and others at UTMSI were generous in their assistance and support. M.R.F. was partially supported by a UGA Graduate School Assistantship. J. T. Hollibaugh supported and encouraged the development of this manuscript. M.R.F. and H.L.M. were supported by the NSF Georgia Coastal Ecosystems LTER grant (OCE-9982133). We are grateful for the comments and suggestions of the anonymous reviewers who reviewed an earlier draft of this manuscript.

\section{LITERATURE CITED}

Agis M, Granda A, Dolan JR (2007) A cautionary note: examples of possible microbial community dynamics in dilution grazing experiments. J Exp Mar Biol Ecol 341:176-183

Banse K (1982) Cell volumes, maximal growth-rates of unicellular algae and ciliates, and the role of ciliates in the marine pelagial. Limnol Oceanogr 27:1059-1071

Boissonneault-Cellineri KR, Mehta M, Lonsdale DJ, Caron DA (2001) Microbial food web interactions in two Long Island embayments. Aquat Microb Ecol 26:139-155

Buskey EJ, Hyatt CJ (1995) Effects of the Texas (USA) 'brown tide' alga on planktonic grazers. Mar Ecol Prog Ser 126:285-292

Calbet A, Landry MR (2004) Phytoplankton growth, microzooplankton grazing, and carbon cycling in marine systems. Limnol Oceanogr 49:51-57

Calbet A, Saiz E (2005) The ciliate-copepod link in marine ecosystems. Aquat Microb Ecol 38:157-167

Calbet A, Landry MR, Nunnery S (2001) Bacteria-flagellate interactions in the microbial food web of the oligotrophic subtropical North Pacific. Aquat Microb Ecol 23:283-292

- Carrias JF, Thouvenot A, Amblard C, Sime-Ngando T (2001) Dynamics and growth estimates of planktonic protists during early spring in Lake Pavin, France. Aquat Microb Ecol 24:163-174

Christoffersen K, Gonzalez JM (2003) An approach to measure ciliate grazing on living heterotrophic nanoflagellates. Hydrobiologia 491:159-166 
Dolan JR, Perez MT (2000) Costs, benefits and characteristics of mixotrophy in marine oligotrichs. Freshw Biol 45:227-238

Dolan JR, Gallegos CL, Moigis A (2000) Dilution effects on microzooplankton in dilution grazing experiments. Mar Ecol Prog Ser 200:127-139

Evans GT, Paranjape MA (1992) Precision of estimates of phytoplankton growth and microzooplankton grazing when the functional-response of grazers may be nonlinear. Mar Ecol Prog Ser 80:285-290

Fileman E, Burkill P (2001) The herbivorous impact of microzooplankton during two short-term Lagrangian experiments off the NW coast of Galicia in summer 1998. Prog Oceanogr 51:361-383

First MR, Lavrentyev PJ, Jochem FJ (2007) Patterns of microzooplankton growth in dilution experiments across a trophic gradient: implications for herbivory studies. Mar Biol 151:1929-1940

Gallegos CL (1989) Microzooplankton grazing on phytoplankton in the Rhode River, Maryland: nonlinear feeding kinetics. Mar Ecol Prog Ser 57:23-33

Gallegos CL, Vant WN, Safi KA (1996) Microzooplankton grazing of phytoplankton in Manukau Harbour, New Zealand. N Z J Mar Freshw Res 30:423-434

Hansen PJ, Calado AJ (1999) Phagotrophic mechanisms and prey selection in free-living dinoflagellates. J Eukaryot Microbiol 46:382-389

Hansen B, Bjornsen PK, Hansen PJ (1994) The size ratio between planktonic predators and their prey. Limnol Oceanogr 39:395-403

Jürgens K, Wickham SA, Rothhaupt KO, Santer B (1996) Feeding rates of macro- and microzooplankton on heterotrophic nanoflagellates. Limnol Oceanogr 41:1833-1839

Landry MR (1993) Estimating rates of growth and grazing mortality of phytoplankton by the dilution method. In: Kemp PF, Sherr BF, Sherr EB, Cole JJ (eds) Handbook of methods in aquatic microbial ecology. Lewis Publishers, Boca Raton, FL, p 715-722

Landry MR, Hassett RP (1982) Estimating the grazing impact of marine micro-zooplankton. Mar Biol 67:283-288

> Landry MR, Kirshtein J, Constantinou J (1995) A refined dilution technique for measuring the community grazing impact of microzooplankton, with experimental tests in the central equatorial Pacific. Mar Ecol Prog Ser 120:53-63

Liu HB, Dagg MJ, Wu CJ, Chiang KP (2005) Mesozooplankton consumption of microplankton in the Mississippi River plume, with special emphasis on planktonic ciliates. Mar Ecol Prog Ser 286:133-144

Menden-Deuer S, Lessard EJ (2000) Carbon to volume relationships for dinoflagellates, diatoms, and other protist plankton. Limnol Oceanogr 45:569-579

Miller HL III, Meile C, Burd AB (2007) A novel 2D model of internal $\mathrm{O}_{2}$ dynamics and $\mathrm{H}_{2} \mathrm{~S}$ intrusion in seagrasses. Ecol Model 205:365-380

Moigis AG (2006) The clearance rate of microzooplankton as the key element for describing estimated non-linear dilution plots demonstrated by a model. Mar Biol 149: 743-762

Editorial responsibility: Karel Šimek, České, Budějovice, Czech Republic
Naustvoll LJ (2000) Prey size spectra in naked heterotrophic dinoflagellates. Phycologia 39:448-455

Ohman MD, Snyder RA (1991) Growth kinetics of the omnivorous oligotrich ciliate Strombidium sp. Limnol Oceanogr 36:922-935

Premke K, Arndt H (2000) Predation on heterotrophic flagellates by protists: food selectivity determined using a livestaining technique. Arch Hydrobiol 150:17-28

Press WH, Blannery BP, Teukolsky SA, Vetterling WT (1988) Numerical recipes in C: the art of scientific computing. Cambridge University Press, Cambridge

Putt M, Stoecker DK (1989) An experimentally determined carbon:volume ratio for marine 'oligotrichous' ciliates from estuarine and coastal waters. Limnol Oceanogr 34: 1097-1103

Reckermann M, Veldhuis MJW (1997) Trophic interactions between picophytoplankton and micro- and nanozooplankton in the western Arabian Sea during the NE monsoon 1993. Aquat Microb Ecol 12:263-273

Rose JM, Caron DA (2007) Does low temperature constrain the growth rates of heterotrophic protists? Evidence and implications for algal blooms in cold waters. Limnol Oceanogr 52:886-895

Rublee PA, Gallegos CL (1989) Use of fluorescently labelled algae (FLA) to estimate microzooplankton grazing. Mar Ecol Prog Ser 51:221-227

> Sanders RW (1995) Seasonal distributions of the photosynthesizing ciliates Laboea strobila and Myrionecta rubra (=Mesodinium rubrum) in an estuary of the Gulf of Maine. Aquat Microb Ecol 9:237-242

Sarnelle O (2003) Nonlinear effects of an aquatic consumer: causes and consequences. Am Nat 161:478-496

Schnetzer A, Caron DA (2005) Copepod grazing impact on the trophic structure of the microbial assemblage of the San Pedro Channel, California. J Plankton Res 27:959-971

Sherr EB, Sherr BF (2002) Significance of predation by protists in aquatic microbial food webs. Antonie Leeuwenhoek 81:293-308

Stoecker DK (1999) Mixotrophy among dinoflagellates. J Eukaryot Microbiol 46:397-401

Stoecker DK, Capuzzo JM (1990) Predation on Protozoa: its importance to zooplankton. J Plankton Res 12:891-908

Straile D (1997) Gross growth efficiencies of protozoan and metazoan zooplankton and their dependence on food concentration, predatoR-prey weight ratio, and taxonomic group. Limnol Oceanogr 42:1375-1385

Strom SL, Brainard MA, Holmes JL, Olson MB (2001) Phytoplankton blooms are strongly impacted by microzooplankton grazing in coastal North Pacific waters. Mar Biol 138:355-368

Waterhouse TY, Welschmeyer NA (1995) Taxon-specific analysis of microzooplankton grazing rates and phytoplankton growth rates. Limnol Oceanogr 40:827-834

Welschmeyer NA (1994) Fluorometric analysis of chlorophyll $a$ in the presence of chlorophyll $b$ and pheopigments. Limnol Oceanogr 39:1985-1992

Wetzel RG, Likens GE (1991) Limnological analysis, 2nd edn. Springer-Verlag, New York

Submitted: July 14, 2008; Accepted: November 24, 2008 Proofs received from author(s): February 13, 2009 